\title{
Refugee Health During the Covid-19 Pandemic: A Review of Global Policy Responses
}

This article was published in the following Dove Press journal:

Risk Management and Healthcare Policy

\section{Sigrid Lupieri (D)}

Department of Politics and International Studies, Centre of Development Studies, University of Cambridge, Cambridge, UK

Correspondence: Sigrid Lupieri Emailsml48@cam.ac.uk

\begin{abstract}
Refugees and displaced persons have been severely affected by the Covid-19 pandemic. Yet findings from this narrative review reveal that the health needs of refugees have been largely neglected within global healthcare responses. Such gaps include: (1) responding to the needs of refugees in camps and detention centers; (2) providing adequate public health information; (3) providing access to healthcare and mental health services; (4) and including refugees as decision-makers within health responses. More research is urgently needed to investigate why these gaps exists and to provide recommendations for improving the inclusiveness of healthcare policies during a pandemic.
\end{abstract}

Keywords: refugees, Covid-19, pandemic, healthcare, global policy, review

\section{Introduction}

There are an estimated 80 million forcibly displaced persons - including refugees in the world today. ${ }^{1}$ While displaced persons are highly heterogeneous in terms of legal and socioeconomic status, in many cases their uncertain or temporary residency status places them at increased risk for poor healthcare access, quality, and outcomes. ${ }^{2}$ Refugees are frequently excluded from national healthcare systems, including affordable insurance and healthcare services, and face deeply entrenched inequalities such as socio-cultural barriers, xenophobic attitudes among healthcare professionals, and a higher incidence of non-communicable diseases. ${ }^{2,3}$ Refugees with no legal right to reside in the countries they are in frequently live on the margins of society with little access to essential services. ${ }^{4}$

Since the World Health Organization declared the novel coronavirus a Public Health Emergency of International Concern in March 2020, the crisis has deeply affected the health and wellbeing of refugees and displaced persons. ${ }^{5,6}$ Entrenched inequalities in host countries not only increase the exposure of refugees to health risks in a pandemic, but also magnify the challenges to accessing adequate healthcare services as compared to national populations. Many refugees live in overcrowded housing and are disproportionately represented in workplaces that place them at risk of exposure to Covid-19 such as factories, production plants, and frontline healthcare work. ${ }^{7,8}$ To date, international health policies affecting refugees have varied considerably. In a few notable cases, governments have taken steps to mitigate the impact of the pandemic on their refugee and migrant populations. In Portugal, for instance, refugees and foreign-born migrants were granted temporary citizenship rights to facilitate their access to healthcare services. ${ }^{9}$ In the UK, several thousands of rejected asylum seekers were provided with accommodation ${ }^{9}$ and, in 
Thailand, Covid-19 testing and treatment were offered free of cost to migrants and refugees. ${ }^{10}$

In most cases, however, efforts to contain the spread of Covid-19 have not only led to the tightening of national borders, but have been used to justify legally dubious, hardline policies towards refugees and migrants. ${ }^{11}$ Moreover, reports have emerged of illegal deportations and human rights violations justified by the COVID-19 response. ${ }^{9}$ Some refugees arriving to the EU by sea have been refused assistance or have been pushed back in violation of international refugee and maritime law.

Recent health scholarship has begun to evaluate global government responses to Covid-19 and the impact of the pandemic on national healthcare systems. Yet so far little is known of how such policy responses affect displaced persons around the world. Amid growing numbers of refugees and displaced persons and one of the largest shortfalls in humanitarian funding to date, a better understanding of the needs and challenges that refugees face during the Covid-19 pandemic is urgently needed. This narrative review contributes to filling this gap by examining the strategies and effectiveness of government policies in meeting the healthcare needs of refugees during the pandemic, and by providing recommendations for policy and research.

\section{Methods}

This narrative review is based on keyword-based searches of three databases of peer-reviewed publications within the medical and social sciences: PubMed, Scopus, and SSRN. These searches were complemented by searches across databases carrying material specifically relating to humanitarian responses, such as Reliefweb, in addition to searches of grey literature databases such as OpenGrey.
For peer-reviewed literature searches, a list of keywords was used to ensure broad literature coverage given the breadth of the topic and the range of evidence types potentially relevant to the discussion. These searches included the following keywords: "refugees", "healthcare", and "Covid-19".

Table 1 shows the inclusion and exclusion criteria, which were applied to all reviewed articles. The inclusion and exclusion criteria focused on the year of publication, language, the type of publication, and the focus of the study. This review includes articles published between March 2020 - when the WHO declared Covid-19 a pandemic - and January 2021. All peer-reviewed article types such as systematic reviews and meta-analyses, reviews, experimental studies, observational studies, commentaries and editorials published in English were included. Books, magazine and newspaper articles were excluded, as were studies that focused only on the health of migrants rather than on refugees or asylum seekers. Similarly, studies that did not address the central research question - how are the healthcare needs of refugees being met during the Covid-19 pandemic? - were excluded. The inclusion of grey literature reports was based on a subjective assessment of the relevance of the content to this review.

\section{Findings}

The search of peer-reviewed databases yielded 64 results. After discounting duplicate articles, 28 publications were considered relevant and thus included in the review. As shown in Table 2, these publications present a varied geographic emphasis, ranging from the Syrian refugee response in Turkey $^{12}$ to the challenges faced by refugees from Bhutan and Burma in the US. ${ }^{13}$ The single most

Table I Inclusion and Exclusion Criteria for the Study Selection

\begin{tabular}{|l|l|l|}
\hline Criterion & Inclusion & Exclusion \\
\hline Timeframe & March 2020-January 202I & $\begin{array}{l}\text { Articles outside of the 2020-2021 } \\
\text { timeframe }\end{array}$ \\
\hline Language & English/full article & Non-English/abstract \\
\hline Source & Articles published in peer-reviewed journals or in the grey literature & Books, magazines, newspapers \\
\hline Location & All countries & None \\
\hline Setting & High- and low-income countries, refugee camps, detention centers and host communities & None \\
\hline Participants & Refugees and asylum seekers & Studies only focusing on migrants \\
\hline Focus & Healthcare responses to Covid-19 involving refugees & Studies not related to the study focus \\
\hline
\end{tabular}


Table 2 Geographic Focus of Selected Studies

\begin{tabular}{|l|l|l|}
\hline Region & Setting & $\begin{array}{l}\text { Number of } \\
\text { Studies }\end{array}$ \\
\hline Africa & Kenya, Uganda, sub-Saharan Africa & 2 \\
Asia & Bangladesh & 5 \\
Europe & Serbia, Greece, UK & 4 \\
Latin America & Brazil & 1 \\
Northern America & United States, Canada & 7 \\
Middle East & Iran, Turkey & 4 \\
Global & N/A & 5 \\
\hline
\end{tabular}

widely represented regional focus, with a total of 11 publications, is on high-income countries with a particular emphasis on Europe, the US and Canada.

Other regional studies focus on the Rohingya refugee crisis in Bangladesh (five articles) and on refugee crises in the Middle East region (four articles), including in Turkey and Iran. Five articles present a global perspective on refugees and health, and two studies address refugee health in Africa, more specifically in Kenya, Uganda and sub-Saharan Africa.

Findings show that refugees face additional barriers and challenges in accessing adequate healthcare services as compared to citizens. Yet government responses have largely failed to account for the particular needs and vulnerabilities of the refugees and migrants residing within their borders. Four significant gaps emerge within national and international health responses during the Covid-19 pandemic: (1) a lack of attention to the needs of refugees in camps and detention centers; (2) a lack of adequate public health information; (3) a lack of inclusive access to health and mental health services; (4) and the exclusion of refugees from decision-making processes.

Recommendations for overcoming such gaps call for a more widespread use of online medical platforms and telehealth as a means for improving the accessibility of health and mental health services. From a policy perspective, recommendations include halting the deportation of refugees, improving public health messaging for marginalized communities, incorporating refugee camps within national health plans, and extending access to health coverage to non-citizens. In what follows, I situate these findings within our current understanding of refugee health and healthcare responses in refugee settings.

\section{Discussion}

Since Covid-19 was declared a pandemic in March 2020, a rapidly growing number of studies has highlighted the effects of the crisis on global healthcare systems and, by extension, on refugee and migrant populations. Though the majority of available studies to date focus on healthcare policies affecting refugees in high-income countries, particularly in the US and Canada, the conclusions and recommendations of such studies are surprisingly consistent across geographic areas. Whether in high- or low-income settings, government responses have largely failed to overcome four significant gaps in meeting the healthcare needs of their displaced populations.

First, the healthcare needs of refugees living in overcrowded conditions in refugee camps and detention centers in both high- and low-income settings have been largely overlooked. In Bangladesh, for instance, an estimated 740,000 Rohingya refugees live in overcrowded and unhygienic conditions with inadequate access to clean drinking water and healthcare, and a lack of opportunities for quarantining and isolating sick individuals. ${ }^{14-17}$ Modeling studies predict that, without immediate action, Covid-19 will spread unchecked within the camps, causing high levels of morbidity and mortality, particularly among older and vulnerable refugees. ${ }^{18}$

In the US, refugees and migrants confined to crowded detention centers are particularly vulnerable to disease outbreaks. Even before the pandemic, unsanitary conditions and poor ventilation and hygiene had caused outbreaks of the flu, mumps and other communicable diseases. ${ }^{19}$ So far, US Immigration and Customs Enforcement has failed to provide transparent and comprehensive information about the spread of Covid-19 throughout its detention centers. ${ }^{19}$ Some data suggest that the virus is prevalent, with an estimated 1200 cases detected across 52 centers. One center reported that half of its detainees had contracted the virus. ${ }^{8}$

Outbreaks have similarly been recorded in detention centers in Germany and Portugal, and in refugee camps in Greece. In the Moria camp in Greece, for instance, more than 1300 refugees share a single water tap and an estimated 5000 people in the area surrounding the camp have no access to water, toilets, showers or electricity. Though modeling simulations predict that Covid-19 will spread rapidly within the Moria camp, ${ }^{20}$ governments in the EU have so far failed to include refugee camps within their national response plans. ${ }^{11}$

Second, national responses have frequently neglected to provide adequate public health information to refugees. In Bangladesh, a government ban on the use of the Internet since September 2019 has limited access to mobile data in refugee camps and hindered the dissemination of vital 
public health information. ${ }^{15}$ In Turkey, Iran, Kenya and Uganda, many refugees lack access to tailored, trustworthy information about Covid-19 and are frequently exposed to rumors and harmful misinformation which can have severe effects on the continued spread of the virus. ${ }^{21,22}$

Third, government responses have largely failed to address the particular challenges that refugees face in accessing health and mental health services. This is of particular urgency at a time when refugees face increased exposure to Covid-19 due in part to their overrepresentation in the essential workforce and in precarious, lowincome jobs that offer few safeguards to protect employees from the virus. ${ }^{7,13}$ In the US, for example, undocumented immigrants and refugees in low-income employment often lack health insurance or access to primary care services and are excluded from government relief packages. ${ }^{7}$

When it comes to mental health, refugees generally tend to suffer from higher rates of PTSD, anxiety and depression as compared to the general population. ${ }^{2}$ Moreover, studies show that refugees frequently exhibit low levels of trust in authorities and institutions due to previous negative experiences in their home countries. Unsurprisingly, the global health crisis appears to be generating increased levels of anxiety among refugees, triggering past traumatic memories and reactions, and aggravating pre-existing mental health conditions. ${ }^{23}$

Studies indicate that post-traumatic stress disorder can be exacerbated by feelings of isolation and of not being in control of one's circumstances. ${ }^{24}$ Lockdowns, increased police presence, and tracing apps employed in countries such as Germany, Israel, Singapore, Hong Kong and the UK have in many cases heightened a sense of fear and mistrust of authorities among refugees. ${ }^{23}$ Similarly, visions of empty streets and news of high mortality rates can bring back traumatic memories of having witnessed conflict, death and other epidemics such as cholera. ${ }^{24}$ Yet few mental health services catering to the needs of refugees are available or accessible within national health responses. $^{25}$

Fourth, refugees are rarely included within policy decision-making and as active participants in healthcare responses. Several studies highlight the positive contributions that refugees can make to their communities and host societies through their low-paid work in difficult settings, ${ }^{4}$ as trained medical workers, ${ }^{19}$ and as community leaders and organizers. ${ }^{21}$ A study on humanitarian health interventions in Kenya and Uganda shows that relying on refugeeled organizations can be a successful model for delivering essential services and disseminating public health information. $^{21}$

The underlying reasons that account for the exclusion of refugees from healthcare responses during the pandemic are little discussed in the literature. In some cases, inequitable access to healthcare services is attributed to an inherent xenophobia towards refugees who are increasingly stigmatized and considered a potential threat to public health. ${ }^{26,27}$ In other cases, research suggests that governments have instrumentalized the Covid-19 pandemic as a means to justify harsh or illegal measures aimed at curbing migration and limiting the rights of refugees. ${ }^{11}$ In Brazil, for instance, refugees not only face widespread discrimination within the healthcare system, but have also been particularly affected by government responses, which include halting immigration and suspending naturalization processes. ${ }^{28}$ In Serbia, Šantić and Antić argue that the international response to the presence of more than 9000 refugees is an example of the profoundly politicized dimensions of refugee health during the pandemic. Here, major political powers such as Russia, China and the EU have been seen to employ "coronavirus diplomacy" to expand their spheres of influence in a geopolitically strategic country through the donation of medical equipment, humanitarian aid, and loans. ${ }^{29}$

Overall, there is agreement among scholars that only with strong and concerted national responses that include refugees, migrants, and marginalized populations can governments hope to slow the spread of the virus and mitigate its effects. In the absence of more inclusive responses, the risk is that the virus will spread unchecked among vulnerable and mobile populations, prolonging the pandemic and presenting a threat to global health security. ${ }^{30}$

\section{Recommendations and Limitations}

When it comes to addressing the gaps in government responses to the needs of refugees during the Covid-19 pandemic, scholarship points to two sets of recommendations: technological solutions and policy responses. Technological solutions include increasing the use of online platforms as a means to monitoring public health and overcoming the physical barriers that refugees face in accessing healthcare services. Such mobile health interventions could collect health data for assessment, help refugees navigate the healthcare systems of their host countries, and provide reliable public health information directly to users in various languages. In particular, teletherapy could provide easier access to counselling and 
other mental health services to refugees from the relative safety of their homes. ${ }^{24}$

From a policy standpoint, there are several recommendations for including refugees in pandemic responses. First, governments should issue a temporary suspension of deportations of asylum seekers. ${ }^{4}$ Second, national policies should focus on improving the working conditions of low-wage and frontline employees by increasing safety measures such as mask wearing and physical distancing. ${ }^{8}$ Third, public health messaging should target refugee communities through culturally sensitive and linguistically appropriate resources, and the use of medical interpreters. ${ }^{31}$

Fourth, governments should recognize the leadership potential and contributions that refugees can make to their communities and host countries. Responses should empower refugee-led organizations to conduct communication campaigns, deliver essential services, conduct contact tracing, and help shape social norms. ${ }^{21}$ Refugees who have trained as medical professionals, but whose credentials are not recognized within their host countries, should be allowed to deliver healthcare services. ${ }^{21}$ In the US, an innovative program allows the International Rescue Committee to identify immigrants and refugees who have foreign medical training and who may be eligible for temporary licenses. With an estimated 165,000 refugees and immigrants with medical training who have been unable to utilize their credentials, this program is providing support to a strained healthcare system facing a shortage of medical professionals. ${ }^{19}$

Finally, responses should include refugee camps within national and regional strategies, with plans for reducing overcrowding and providing improved shelter and sanitation. ${ }^{32}$ There is widespread agreement that healthcare coverage - particularly during a pandemic - should be available and accessible to all. ${ }^{11,27}$ Governments should extend unemployment insurance and benefit packages to refugees. ${ }^{19}$ In countries that are participating in the Covid19 Global Access (COVAX) scheme for a fairer vaccine distribution, migrants and refugees should be explicitly included among "at risk" populations and should be prioritized within vaccination campaigns. ${ }^{8,9}$

This review identified the main gaps within global healthcare responses in meeting the needs of refugees. Given the relatively short time span since the beginning of the pandemic, many of the studies included in this review are based on small sample sizes and observation. There is little research to date on the particular challenges that frequently marginalized groups such as women, older refugees, and refugees with disabilities face within the same refugee population. A particularly neglected topic are the specific health needs of refugees with underlying medical conditions and chronic diseases who not only require specialized care and disease management, but are also particularly vulnerable to the effects of Covid-19.

More research that includes strong empirical evidence and, in particular, comparative perspectives is needed. Future avenues for research should place a greater emphasis on the policy challenges facing refugee host states in the Global South, where an estimated $80 \%$ of the world's refugees reside. ${ }^{33}$ Lastly, comparative research examining the policy responses among various countries and highlighting examples of good practice would be a particularly welcome addition to our current understanding of refugee health during Covid-19.

\section{Conclusion}

Global healthcare responses to the Covid-19 pandemic largely fail to address the specific needs of refugees. Such gaps include responding to the needs of refugees in camps and detention centers, providing adequate public health information, providing access to healthcare and mental health services, and including refugees in decisionmaking processes. Further research on refugee health during the Covid-19 pandemic is urgently needed. This research should not only focus on the underlying political factors that affect the decisions of states to include refugees within their healthcare policies, but also on the active roles that refugees and refugee-led organizations can and do play within crisis responses. Moreover, research on host states in Africa and other parts of the Global South - where more than $80 \%$ of the world's refugee reside - should be a priority.

\section{Disclosure}

The author reports no conflicts of interest in this work.

\section{References}

1. UNHCR. Figures at a Glance [WWW Document]. UNHCR; 2019. Available from: https://www.unhcr.org/figures-at-a-glance.html. Accessed January 21, 2021.

2. Lebano A, Hamed S, Bradby H, et al. Migrants' and refugees' health status and healthcare in Europe: a scoping literature review. $B M C$ Public Health. 2020;20(1):1039. doi:10.1186/s12889-020-08749-8

3. Robertshaw L, Dhesi S, Jones LL. Challenges and facilitators for health professionals providing primary healthcare for refugees and asylum seekers in high-income countries: a systematic review and thematic synthesis of qualitative research. BMJ Open. 2017;7(8): e015981. doi:10.1136/bmjopen-2017-015981

4. Bhopal RS. COVID-19: immense necessity and challenges in meeting the needs of minorities, especially asylum seekers and undocumented migrants. Public Health. 2020;182:161-162. doi:10.1016/j. puhe.2020.04.010 
5. Kondilis E, Puchner K, Veizis A, Papatheodorou C, Benos A. Covid19 and refugees, asylum seekers, and migrants in Greece. $B M J$. 2020;369:m2168. doi:10.1136/bmj.m2168

6. Kuy S, Tsai R, Bhatt J, et al. Focusing on vulnerable populations during COVID-19. Acad Med. 2020;95(11):e2-e3. doi:10.1097/ ACM.0000000000003571

7. Endale T, St Jean N, Birman D. COVID-19 and refugee and immigrant youth: a community-based mental health perspective. Psychol Trauma Theory Res Pract Policy. 2020;12(S1):S225-S227. doi: $10.1037 /$ tra0000875

8. Greenaway C, Hargreaves S, Barkati S, et al. COVID-19: exposing and addressing health disparities among ethnic minorities and migrants. J Travel Med. 2020;27(7). doi:10.1093/jtm/taaa113

9. Mukumbang FC. Are asylum seekers, refugees and foreign migrants considered in the COVID-19 vaccine discourse? BMJ Glob Health. 2020;5(11):e004085. doi:10.1136/bmjgh-2020-004085

10. Shadmi E, Chen Y, Dourado I, et al. Health equity and COVID-19: global perspectives. Int $J$ Equity Health. 2020;19(1):104. doi:10.1186/s12939-020-01218-z

11. Hargreaves S, Kumar BN, McKee M, Jones L, Veizis A. Europe's migrant containment policies threaten the response to covid-19. BMJ. 2020;368:m1213. doi: $10.1136 / \mathrm{bmj} . \mathrm{m} 1213$

12. Budak F, Bostan S. The effects of Covid-19 pandemic on syrian refugees in Turkey: the Case of Kilis. Soc Work Public Health. 2020;35(7):579-589. doi:10.1080/19371918.2020.1806984

13. Zhang M, Gurung A, Anglewicz P, Yun K. COVID-19 and immigrant essential workers: Bhutanese and Burmese Refugees in the United States. Public Health Rep. 2021;136(1):117-123. doi:10.1177/ 0033354920971720

14. Banik R, Rahman M, Hossain MM, Sikder MT, Gozal D. COVID-19 pandemic and Rohingya refugees in Bangladesh: what are the major concerns? Glob Public Health. 2020;15(10):1578-1581. doi:10.1080/ 17441692.2020.1812103

15. Barua A, Karia RH. Challenges faced by Rohingya Refugees in the COVID-19 pandemic. Ann Glob Health. 2020;86(1):129. doi:10.5334/aogh.3052

16. Naz Isha S, Hoque Apu E, Siddika N, Kabir R. Oral health of the Rohingya Refugees in Bangladesh and the COVID-19 Pandemic (SSRN Scholarly Paper No. ID 3667950). Rochester, NY: Social Science Research Network; 2020. doi:10.2139/ssrn.3667950

17. Truelove S, Abrahim O, Altare C, Azman A, Spiegel P. COVID-19: projecting the impact in Rohingya Refugee Camps and Beyond (SSRN Scholarly Paper No. ID 3561565). Rochester, NY: Social Science Research Network; 2020a. doi:10.2139/ssrn.3561565

18. Truelove S, Abrahim O, Altare C, et al. The potential impact of COVID-19 in refugee camps in Bangladesh and beyond: a modeling study. PLoS Med. 2020b;17(6):e1003144. doi:10.1371/ journal.pmed.1003144

19. Grant A. Coronavirus, refugees, and Government Policy: the State of U.S. Refugee resettlement during the coronavirus pandemic. World Med Health Policy. 2020;12(3):291-299. doi:10.1002/wmh3.362
20. Gilman RT, Mahroof-Shaffi S, Harkensee C, Chamberlain AT. Modelling interventions to control COVID-19 outbreaks in a refugee camp. BMJ Glob Health. 2020;5(12):e003727. doi:10.1136/bmjgh-2020-003727

21. Betts A, Easton-Calabria E, Pincock K. Localising public health: refugee-led organisations as first and last responders in COVID-19. World Dev. 2021;139:105311. doi:10.1016/j.worlddev.2020.105311

22. Salmani I, Seddighi H, Nikfard M. Access to health care services for Afghan Refugees in Iran in the COVID-19 pandemic. Disaster Med Public Health Prep. 2020;14(4):e13-e14. doi:10.1017/dmp.2020.240

23. Rees S, Fisher J. COVID-19 and the mental health of people from refugee backgrounds. Int J Health Serv Plan Adm Eval. 2020;50 (4):415-417. doi:10.1177/0020731420942475

24. Mattar S, Piwowarczyk LA. COVID-19 and U.S.-based refugee populations: commentary. Psychol Trauma Theory Res Pract Policy. 2020;12(S1):S228-S229. doi:10.1037/tra0000602

25. Kakaje A, Fadel A, Ghareeb A. Mental distress and psychological disorders of Syrians in Fragile Syria and multiple countries related to COVID-19 (SSRN Scholarly Paper No. ID 3631240). Rochester, NY: Social Science Research Network; 2020. doi:10.2139/ssrn.3631240

26. Alemi Q, Stempel C, Siddiq H, Kim E. Refugees and COVID-19: achieving a comprehensive public health response. Bull World Health Organ. 2020;98(8):510-510A. doi:10.2471/BLT.20.271080

27. Chen YYB, 2020. Migrant health in a time of pandemic: fallacies of US-versus-them (SSRN Scholarly Paper No. ID 3651501). Rochester, NY: Social Science Research Network.

28. Martuscelli PN. How are refugees affected by brazilian responses to COVID-19? Rev Adm Publica. 2020;54:1446-1457. doi:10.1590/ 0034-761220200516x

29. Šantić D, Antić M. Serbia in the time of COVID-19: between "corona diplomacy", tough measures and migration management. Eurasian Geogr Econ. 2020;61(4-5):546-558. doi:10.1080/ 15387216.2020 .1780457

30. Alawa J, Alawa N, Coutts A, Sullivan R, Khoshnood K, Fouad FM. Addressing COVID-19 in humanitarian settings: a call to action. Confl Health. 2020;14(1):64. doi:10.1186/s13031-020-00307-8

31. Clarke SK, Kumar GS, Sutton J, et al. Potential Impact of COVID-19 on recently resettled refugee populations in the United States and Canada: perspectives of refugee healthcare providers. $J$ Immigr Minor Health. 2020. doi:10.1007/s10903-020-01104-4

32. Kousi T, Mitsi L-C, Simos J. The early stage of COVID-19 outbreak in Greece: a Review of the National Response and the Socioeconomic Impact. Int J Environ Res Public Health. 2021;18 (1):322. doi:10.3390/ijerph18010322

33. Amnesty International. Global facts and figures about refugees [WWW Document]; 2021. Available from: https://www.amnesty. org/en/what-we-do/refugees-asylum-seekers-and-migrants/globalrefugee-crisis-statistics-and-facts/. Accessed January 24, 2021.
Risk Management and Healthcare Policy

\section{Publish your work in this journal}

Risk Management and Healthcare Policy is an international, peerreviewed, open access journal focusing on all aspects of public health, policy, and preventative measures to promote good health and improve morbidity and mortality in the population. The journal welcomes submitted papers covering original research, basic science, clinical \& epidemiological studies, reviews and evaluations, guidelines, expert opinion and commentary, case reports and extended reports. The manuscript management system is completely online and includes a very quick and fair peer-review system, which is all easy to use. Visit http://www.dovepress.com/testimonials.php to read real quotes from published authors. 